\title{
Thermodynamics and Kinetics of Martensitic Transformation in Ni-Mn-based Magnetic Shape Memory Alloys
}

\author{
Xiao X $\mathrm{u}^{1}$, Ryosuke Kainuma ${ }^{1, a}$, Takumi Kihara ${ }^{2,4}$, Wataru Ito ${ }^{3}$, Masashi Tokunaga ${ }^{4}$, and Takeshi Kanomata ${ }^{5}$ \\ ${ }^{1}$ Department of Materials Science, Tohoku University, Sendai 980-8579, Japan \\ ${ }^{2}$ Institute for Materials Research, Tohoku University, Sendai 980-8577, Japan \\ ${ }^{3}$ Department of Materials and Environmental Engineering, Sendai National College of Technology, Natori 981-1239, Japan \\ ${ }^{4}$ International MegaGauss Science Laboratory, Institute for Solid State Physics, The University of Tokyo, Kashiwa 277-8581, \\ Japan \\ ${ }^{5}$ Research Institute for Engineering and Technology, Tohoku Gakuin University, Tagajo 985-8537, Japan
}

\begin{abstract}
We herein present a review of recent thermodynamic and kinetic studies on Ni-Mn-based magnetic shape memory alloys along with some new data supporting the kinetic discussion. Magnetic phase diagrams and Clausius-Clapeyron relationships are mainly discussed for Ni-Mn-Ga and Ni-Mn-In systems. For the kinetics, a phenomenological model based on Seeger's model is used to describe the temperature dependence of magnetic field hysteresis, as well as the change of hysteresis under different sweeping rates of magnetic fields.
\end{abstract}

\section{Introduction}

Research on Ni-Mn-based magnetic shape memory alloys dates back to 1984 when Webster et al. investigated the ferromagnetic $\mathrm{Ni}_{2} \mathrm{MnGa}$ Heusler alloys showing martensitic transformation [1]. In 1996, Ullakko et al. reported a $0.2 \%$ magnetic field-induced strain (MFIS) in a $\mathrm{Ni}_{2} \mathrm{MnGa}$ Heusler alloy [2]. Since then alloys showing variant rearrangement under a magnetic field in their martensite phase have been categorized as ferromagnetic shape memory alloys (FMSMA) and this field of research has received much attention. Other FMSMAs, such as Fe-Pd [3], Fe-Pt [4], Ni-Mn-Al [5], Ni-Co-Ga [6], Ni-Co-Al [7] and Ni$\mathrm{Fe}-\mathrm{Ga}[8]$, have successively been reported. In Ni-Mn-Ga systems, a huge MFIS of about $9.4 \%$ has been reported in $14 M$ [9] and about $12 \%$ in non-modulated [10] martensites, despite the fact that the output stress is limited to several MPa $[11,12]$.

On the contrary, as first reported by Sutou et al., NiMn- $X(X=\mathrm{In}, \mathrm{Sn}$, and Sb) alloys generally show a large difference in magnetization between the parent and martensite phases $(\Delta M)$ [13]. In the Ni-Co-Mn-In alloy, magnetic field-induced transformation (MFIT) has been realized by reverse martensitic transformation [14]. This group of alloys are called metamagnetic shape memory alloys (MMSMA). Substitutional Ni-Mn-based alloy systems such as Ni-Co-Mn-Sn [15], Ni-Co-Mn-Ga [16] and $\mathrm{Ni}-\mathrm{Co}-\mathrm{Mn}-\mathrm{Al}$ [17], ferrous systems such as $\mathrm{Fe}-\mathrm{Mn}-\mathrm{Al}$ [18], Fe-Mn-Ga [19] and Fe-Mn-Al-Ni [20], as well as cobalt based Co-Cr-Ga-Si alloys [21] have been reported. In these alloys, there is a strong output stress during the

\footnotetext{
${ }^{\text {a} C o r r e s p o n d i n g ~ a u t h o r ' s ~ e-m a i l: ~ k a i n u m a @ m a t e r i a l . t o h o k u . a c . j p ~}$
}

MFIT [22-24] though a strong magnetic field is needed for the realization of MMSMA.

In this article, we review some representative experimental studies on Ni-Mn-based alloys. In the first section, magnetic phase diagrams as well as Clausius-Clapeyron relationships are discussed with a focus on thermodynamic analysis. In the second part, some kinetic studies on $\mathrm{Ni}$ Mn-based alloys are reviewed along with some new data supporting the discussion.

\section{Thermodynamics of Ni-Mn-based Magnetic Shape Memory Alloys}

\subsection{Ni-Mn-Ga- and Ni-Mn-In-typed Phase Diagrams}

Figure 1 shows the experimental phase diagrams of $\mathrm{Ni}_{50} \mathrm{Mn}_{50-x} \mathrm{Ga}_{x}$ and $\mathrm{Ni}_{50} \mathrm{Mn}_{50-x} \mathrm{In}_{x}$ alloy systems. These two systems are chosen here because Ni-Mn-Ga and NiMn-In alloys are representative alloys for FMSMA and MMSMA, respectively. This figure is based on experimental data for $\mathrm{Ni}_{50} \mathrm{Mn}_{50-x} \mathrm{Ga}_{x}$ [26] and $\mathrm{Ni}_{50} \mathrm{Mn}_{50-x} \mathrm{In}_{x}$ [25]. Reference to other consistent reports on the phase diagrams for $\mathrm{Ni}_{50} \mathrm{Mn}_{50-x} \mathrm{In}_{x}[13,27]$ and $\mathrm{Ni}_{50} \mathrm{Mn}_{50-x} \mathrm{Ga}_{x}$ [28] should be made. Both the phase diagram of $\mathrm{Ni}_{50} \mathrm{Mn}_{50-x} \mathrm{Ga}_{x}$ and that of $\mathrm{Ni}_{50} \mathrm{Mn}_{50-x} \mathrm{In}_{x}$ can be divided into four major phase regions, which are as follows:

(I) the paramagnetic parent phase region,

(II) the ferromagnetic parent phase region,

(III) the paramagnetic martensite phase region, and

(IV) the ferromagnetic martensite phase region, 


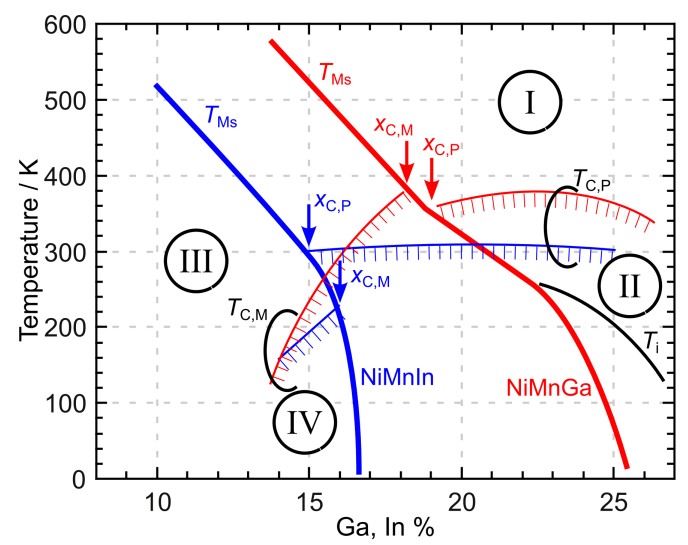

Figure 1. Experimental magnetic phase diagrams of $\mathrm{Ni}_{50} \mathrm{Mn}_{50-x} \mathrm{In}_{x}$ [25] and $\mathrm{Ni}_{50} \mathrm{Mn}_{50-x} \mathrm{Ga}_{x}$ [26]. Martensitic transformation starting temperature $T_{\mathrm{M}_{\mathrm{s}}}$, Curie temperatures of parent $T_{\mathrm{C}, \mathrm{P}}$ and martensite $T_{\mathrm{C}, \mathrm{M}}$ phases are indicated. $x_{\mathrm{C}, i}$ indicates the intersection composition for $T_{\mathrm{M}_{\mathrm{s}}}$ and $T_{\mathrm{C}, i}(i=\mathrm{P}$ or $\mathrm{M})$.

where $x_{\mathrm{C}, i}(i=\mathrm{P}$ or $\mathrm{M})$ indicates the intersection composition for $T_{\mathrm{M}_{\mathrm{s}}}$ and $T_{\mathrm{C}, i}$.

For the $\mathrm{Ni}_{50} \mathrm{Mn}_{50-x} \mathrm{Ga}_{x}$ system, region IV is wide and covers the stoichiometric $\mathrm{Ni}_{2} \mathrm{MnGa}$ composition [1, 29]. Moreover, the Curie temperature of the martensite phase $\left(T_{\mathrm{C}, \mathrm{M}}\right)$ is slightly higher or almost equal to the Curie temperature of the parent phase $\left(T_{\mathrm{C}, \mathrm{P}}\right)$, and the $\Delta M$ in the vicinity of martensitic transformation temperature $\left(T_{\mathrm{M}_{\mathrm{s}}}\right)$ is very small. Similar phase diagrams can be found for $\mathrm{Ni}-\mathrm{Mn}-\mathrm{Ga}$ systems such as in $\mathrm{Ni}_{2+x} \mathrm{Mn}_{1-x} \mathrm{Ga}$ [30-32] and other sections [33, 34]. Moreover, some substitutional quaternary systems such as $\left(\mathrm{Ni}_{52.5} \mathrm{Mn}_{23.5} \mathrm{Ga}_{24}\right)_{100-x} \mathrm{Co}_{x}$ [35], $\mathrm{Ni}_{2} \mathrm{MnGa}_{1-x} \mathrm{Co}_{x}$ [36], Ni-Mn-Ga-Cu [37-39], and Ni-Mn-Ga-Fe [40, 41] systems also show similar behaviors, and a magnetically coupled structural transition, i.e., a direct transition from region I to region IV, can be found in a wide range of compositions.

On the contrary, for the $\mathrm{Ni}_{50} \mathrm{Mn}_{50-x} \mathrm{In}_{x}$ system, region IV is narrow and disappears far from the stoichiometric $\mathrm{Ni}_{2} \mathrm{MnIn}$ composition. Another major difference is that the $T_{\mathrm{C}, \mathrm{P}}$ is generally higher than $T_{\mathrm{C}, \mathrm{M}}$ and transition from region II to region III is possible where a ferromagneticparent-to-paramagnetic-martensite transformation occurs. However, it is of interest that, as reported by Yu et al., this Ni-Mn-In type transition can also be realized with a proper substitution of Co into Ni-Mn-Ga [16]. A clear phase diagram showing this evolution has been reported by Wang et al. [42]. Besides, except for Ga, the phase diagrams for other ternary alloy systems generally show a $T_{\mathrm{C}, \mathrm{P}}$ much higher than $T_{\mathrm{C}, \mathrm{M}}$, as shown by Sutou et al. [13]. This can also be found in other ternary $\mathrm{Ni}_{89-x} \mathrm{Mn}_{x} \mathrm{In}_{11}$ [43] and quaternary $\mathrm{Ni}_{50-x} \mathrm{Co}_{x} \mathrm{Mn}_{50-y} \mathrm{In}_{y}$ [25], $\quad \mathrm{Ni}_{2} \mathrm{Mn}_{1.48-x} \mathrm{Fe}_{x} \mathrm{Sn}_{0.52}$ [44], $\mathrm{Ni}_{50-x} \mathrm{Co}_{x} \mathrm{Mn}_{50-y} \mathrm{Al}_{y}$ [45-47] and $\mathrm{Ni}_{50-x} \mathrm{Co}_{x} \mathrm{Mn}_{50-y} \mathrm{Sn}_{y}$ [48] systems, where a region II to region III transition can be easily found.

A further comparison between the magnetic phase diagrams of $\mathrm{Ni}_{50} \mathrm{Mn}_{50-x} \mathrm{Ga}_{x}$ and $\mathrm{Ni}_{50} \mathrm{Mn}_{50-x} \mathrm{In}_{x}$ in Fig. 1 reveals that the two systems have a similar behavior for the

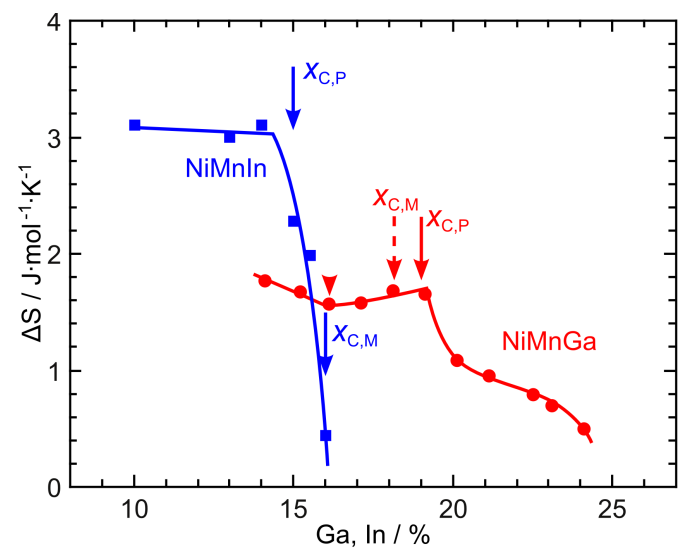

Figure 2. Entropy change during martensitic transformation $\Delta S$ for $\mathrm{Ni}_{50} \mathrm{Mn}_{50-x} \mathrm{Ga}_{x}$ [49] and $\mathrm{Ni}_{50} \mathrm{Mn}_{50-x} \mathrm{In}_{x}$ [25].

composition dependence of magnetic transition temperatures $\left(T_{\mathrm{C}, \mathrm{P}}\right.$ and $\left.T_{\mathrm{C}, \mathrm{M}}\right)$. Moreover, if an extrapolation of $T_{\mathrm{C}, \mathrm{P}}$ and $T_{\mathrm{C}, \mathrm{M}}$ were possible, with the change of composition $Z, \mathrm{Ni}_{50} \mathrm{Mn}_{50-x} \mathrm{Ga}_{x}$ might also show $T_{\mathrm{C}, \mathrm{P}}>T_{\mathrm{C}, \mathrm{M}}$ at about $15 \% \mathrm{Ga}$, and $\mathrm{Ni}_{50} \mathrm{Mn}_{50-x} \mathrm{In}_{x}$ might also show $T_{\mathrm{C}, \mathrm{M}}>T_{\mathrm{C}, \mathrm{P}}$ at about $20 \%$ In compositions. Nevertheless, the $T_{\mathrm{M}_{\mathrm{s}}}$ of the two series systematically differs by about $5 \%$ in $Z$ composition. Specifically, with the increase of Ga or In composition, the martensite phase of $\mathrm{Ni}_{50} \mathrm{Mn}_{50-x} \mathrm{In}_{x}$ disappears whereas the martensite phase of $\mathrm{Ni}_{50} \mathrm{Mn}_{50-x} \mathrm{Ga}_{x}$ remains stable until stoichiometry, which can be considered as the biggest difference between $\mathrm{Ni}_{50} \mathrm{Mn}_{50-x} \mathrm{Ga}_{x}$ and $\mathrm{Ni}_{50} \mathrm{Mn}_{50-x} \mathrm{In}_{x}$ systems.

\subsection{Entropy Change during Martensitic Transformation}

Along with the determination of phase diagrams, which gives information on the change of thermodynamic equilibrium states with variation of composition, investigation of entropy change during first-order martensitic transformation $(\Delta S)$ is also of great importance, as it reveals the Gibbs energy near the equilibrium state when the temperature is subjected to change.

The simplest direct way of obtaining $\Delta S$ is by use of

$$
\Delta S=\Delta L / T
$$

from thermoanalysis, where $\Delta L$ is the latent heat or the enthalpy change $(\Delta H)$ during the martensitic transformation. A graphical meaning of $\Delta S$ is shown in Fig. 3(a). Other ways to determine $\Delta S$ by use of Clausius-Clapeyron equations are discussed in Sec. 2.3.

Figure 2 shows $\Delta S$ for $\mathrm{Ni}_{50} \mathrm{Mn}_{50-x} \mathrm{Ga}_{x}$ [49] and $\mathrm{Ni}_{50} \mathrm{Mn}_{50-x} \operatorname{In}_{x}$ [25] systems. Systematic studies on $\Delta S$ in the Ni-Mn-Ga systems have been intensively performed [50-52] due to its wide interest. For the $\mathrm{Ni}_{50} \mathrm{Mn}_{50-x} \mathrm{Ga}_{x}$ section, with increasing Ga content, the $\Delta S$ increases near $x_{\mathrm{C}, \mathrm{M}}$ and decreases over $x_{\mathrm{C}, \mathrm{P}}$, as shown in Fig. 2 . The composition where $\Delta S$ starts to increase, which is indicated by a small triangle in Fig. 2, does not coincide with $x_{\mathrm{C}, \mathrm{M}}$, which is considered to be the result of short-range 
ordering of the ferromagnetic martensite phase above its $T_{\mathrm{C}, \mathrm{M}}$. Refer to [49] for a detailed discussion. For the $\mathrm{Ni}_{50} \mathrm{Mn}_{50-x} \mathrm{In}_{x}$ system, the most important characteristic is that the $\Delta S$ to the left of $x_{\mathrm{C}, \mathrm{P}}$ shows little change, whereas it abruptly decreases to the right of $x_{\mathrm{C}, \mathrm{P}}$. Reports of a similar tendency of $\Delta S$ can be found in other ternary NiMn-In alloys $[53,54]$. The decrease of $\Delta S$ below $T_{\mathrm{C}, \mathrm{P}}$ by direct measurements can also be found in Sb-doped [55] and Co-doped [56] quaternary systems, as well as in the $\mathrm{Ni}_{50-x} \mathrm{Co}_{x} \mathrm{Mn}_{50-y} \mathrm{Al}_{y}$ system [57]. This common tendency is considered to be the thermodynamic cause of the "thermal transformation arrest phenomenon" [58, 59], where the martensitic transformation is interrupted at a certain temperature during the cooling process.

\subsection{Clausius-Clapeyron Equations}

On the other hand, the Clausius-Clapeyron equations are widely used as they are convenient approaches for indirect measurements of $\Delta S$ due to the first-order nature of the martensitic transformation. By writing the total derivative of Gibbs energy $G$ as

$$
\mathrm{d} G=-S \mathrm{~d} T+V \mathrm{~d} p+M \mathrm{~d} H+l \mathrm{~d} F+\sum_{i} \mu_{i} \mathrm{~d} x_{i},
$$

where $V$ is the molar volume, $p$ is the hydrostatic pressure, $H$ is the magnetic field, $l$ is the length of the sample, $F$ is the uniaxial force, and $\mu_{i}$ is the chemical potential of component $i$. Assuming that $S, V, M, l$ and $\mu_{i}$ show little change in the parent and martensite phases, this deduces the Clausius-Clapeyron equations as [60]

$$
\begin{gathered}
\frac{\mathrm{d} \sigma_{0}}{\mathrm{~d} T}=-\frac{\Delta S}{\varepsilon V}, \\
\frac{\mathrm{d} p_{0}}{\mathrm{~d} T}=-\frac{\Delta S}{\Delta V}, \\
\frac{\mathrm{d} H_{0}}{\mathrm{~d} T}=-\frac{\Delta S}{\Delta M},
\end{gathered}
$$

where $\varepsilon$ is the martensitic transformation strain, $\sigma$ is the uniaxial stress, and the quantities with zero in subscript correspond to their thermodynamic equilibrium states.

Equation 3 is the most commonly used relationship for the investigations of conventional shape memory alloys, as reported for Ni-Ti alloys [61]. Since the martensite phase is uniaxial stress-favored, the application of uniaxial stress usually induces the martensite phase, which is illustrated in Fig. 3(b). In Ni-Mn-based alloy systems, research studies have been done for Ni-Mn-Ga [62], Ni-CoMn-In [14, 63-67] single crystals and Ni-Co-Mn-In [68] and Ni-Co-Mn-Al [69] poly-crystals. On the other hand, this is the phenomenon attributable to the elastocaloric effect [70-72], which is of practical importance.

Equation 4 is effective for the investigation of $\Delta S$ since the samples can be small and polycrystalline, and it is applicable to brittle alloys. Note that hydrostatic pressure stabilizes the phase which has a smaller molar volume. A review article can be found in Ref. [73] and this phenomenon is also utilized in the barocaloric effect [74].
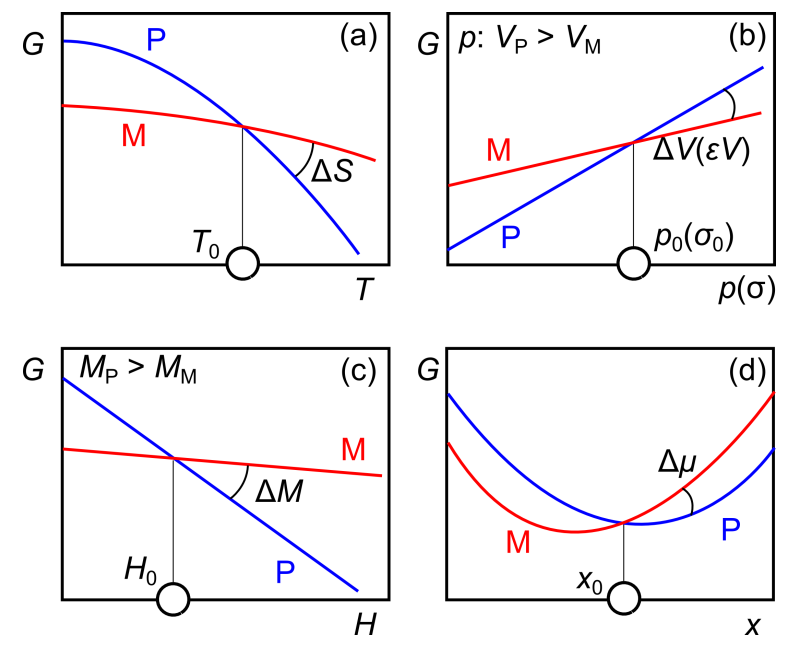

Figure 3. Schematic figures for a better understanding of the Clausius-Clapeyron equations. (a) is an illustration of the definition of $\Delta S$. (b) corresponds to Eqs. 3 and 4. (c) corresponds to Eq. 5. (d) shows an illustration of the chemical potential change which appears in Eq. 6. In (a) to (d), the changes of the intensive properties $\Delta \mathbb{Q}=\left|\partial G_{\mathrm{P}} / \partial \mathbb{P}-\partial G_{\mathrm{M}} / \partial \mathbb{P}\right|_{\mathbb{P}=\mathbb{P}_{0}}$ are geometrically indicated, where $\mathbb{Q}$ and $\mathbb{P}$ stand for the intensive properties and their corresponding external fields, respectively, as shown in Eq. 2.

In Ni-Mn-Ga systems, the molar volume change during martensitic transformation is so small that reports for both a decrease [75, 76] and an increase [77-79] of $T_{\mathrm{M}_{\mathrm{s}}}$ with increasing pressure can be found. In other systems such as Ni-Mn-In [80, 81], Ni-Co-Mn-Ga [82] and Ni-Mn-Fe-Ga [83], positive relationships of $\mathrm{d} T_{\mathrm{M}_{\mathrm{s}}} / \mathrm{d} p$ have been reported by many groups, which is the cause of greater molar volume of the parent phase.

Equation 5 can be found in many reports in the field of Ni-Mn-based alloys both because of the easy access of moderately strong magnetic fields as well as interest in the magnetocaloric effect [84-86]. For Ni-Mn-Ga ternary alloys, the magnetization of martensite phase is greater than that of the parent phase [87], and therefore a strong magnetic field generally raises the $T_{\mathrm{M}_{\mathrm{s}}}$ [88-90]. However, due to the large magnetic anisotropy in Ni-Mn-Ga alloys $[2,91]$, a low magnetic field results in a small decrease of $T_{\mathrm{M}_{\mathrm{s}}}[88,89]$. Nevertheless, for Ni-Mn-In alloys, the magnetization of the parent phase is much greater than that of martensite phase, and thus magnetic fields will effectively decrease the $T_{\mathrm{M}_{\mathrm{s}}}$ [23, 92-96], as is schematically shown in Fig. 2.3(c). In quaternary systems such as Ni-Co-Mn-In [58, 65, 66, 97-101], Ni-Co-Mn-Sn [15, 101, 102], Ni-CoMn-Sb, [101, 103, 104], Ni-Co-Mn-Al [17, 46, 105-107] and Ni-Co-Mn-Ga [16, 108-110], the same relationship of $\Delta M$ as well as MFIT have been found. It should be noted that in most of the above cited studies, magnetization was monitored for the detection of MFIT. Other methods, such as monitoring the electric resistance [99], the variation of sample temperature [100] or the variation of strain [65], have been used. In situ observation of optical microstructure $[98,107,111]$ as well as X-ray diffraction patterns 


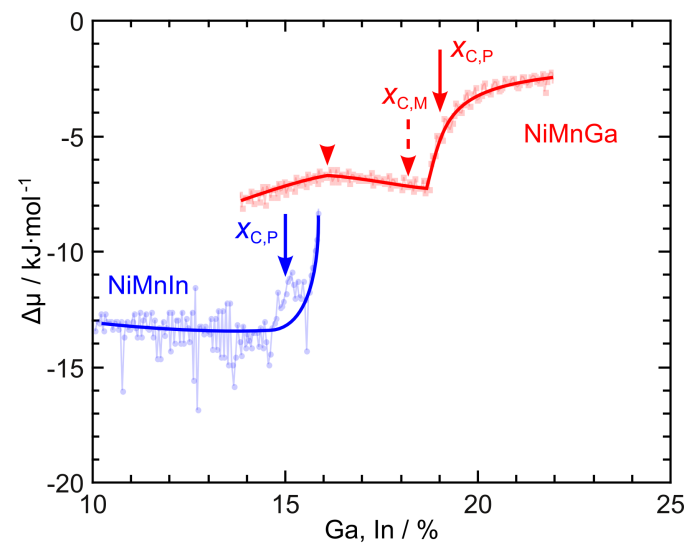

Figure 4. Chemical potential change during martensitic transformation $\Delta \mu$ for $\mathrm{Ni}_{50} \mathrm{Mn}_{50-x} \mathrm{In}_{x}$ and $\mathrm{Ni}_{50} \mathrm{Mn}_{50-x} \mathrm{Ga}_{x}$ systems. Data from Refs.[25-27, 49] were used as in Eq. 6 for the calculation of $\Delta \mu$.

$[106,112]$ have also been utilized as detection methods in the above cited studies.

\subsection{Chemical Potential Change during the Martensitic Transformation}

Figure 3(d) shows another section of the Gibbs energy curves, which are against the composition axis. Following Niitsu et al. [113], from Eq. 2 we have

$$
\frac{\mathrm{d} x_{0}^{Z}}{\mathrm{~d} T}=-\frac{\Delta S}{\Delta \mu_{\mathrm{NiZ}}-\Delta \mu_{\mathrm{NiMn}}},
$$

where a pseudo-binary system of $\mathrm{NiMn}-\mathrm{NiZ}(Z=\mathrm{In}, \mathrm{Ga})$ under equilibrium is considered, with $x_{0}^{Z}$ being the equilibrium composition and $\Delta \mu_{\mathrm{NiZ}}$ and $\Delta \mu_{\mathrm{NiMn}}$ being the chemical potential change for the end-member $\mathrm{NiZ}$ and NiMn phases, respectively. Therefore, $\Delta \mu=\Delta \mu_{\mathrm{NiZ}}-\Delta \mu_{\mathrm{NiMn}}$ can be calculated for $\mathrm{Ni}_{50} \mathrm{Mn}_{50-x} \mathrm{In}_{x}$ and $\mathrm{Ni}_{50} \mathrm{Mn}_{50-x} \mathrm{Ga}_{x}$. The curves shown in Figs. 1 and 2 were traced for the calculation of $\Delta \mu$ and the results are shown in Fig. 4. Note that in Fig. 1 the composition at which $T_{\mathrm{M}_{\mathrm{s}}}$ occurs was used, therefore $\mathrm{d} x_{\mathrm{Ms}}^{Z} / \mathrm{d} T$ was used instead of $\mathrm{d} x_{0}^{Z} / \mathrm{d} T$ for simplicity. It can be seen that $\mathrm{Ni}_{50} \mathrm{Mn}_{50-x} \mathrm{In}_{x}$ generally has a greater absolute value of $\Delta \mu$ compared with that of $\mathrm{Ni}_{50} \mathrm{Mn}_{50-x} \mathrm{Ga}_{x} . \Delta \mu$ also changes at magnetic transitions, as indicated by $T_{\mathrm{C}, \mathrm{P}}$ and $T_{\mathrm{C}, \mathrm{M}}$ in Fig. 4 . Table 1 shows a comparison of $\Delta \mu$ for three alloy systems. The data at around $400 \mathrm{~K}$, which is above the magnetic transitions, are summarized. One can see that $\mathrm{Ni}-\mathrm{Ti}$ has the largest $\Delta \mu$ among the three series because of the large composition dependence of $T_{\mathrm{M}_{\mathrm{s}}}$ as well as the large $\Delta S$. Ni-Mn-Ga and Ni-Mn-In have comparable values of $\mathrm{d} T / \mathrm{d} x_{0}^{Z}$, whereas Ni-Mn-In has a larger value of $\Delta \mu$ because of its large $\Delta S$ at the martensitic transformation. However, an in-depth discussion on $\Delta \mu$, especially for situations near the magnetic transitions, is avoided in this study, though the bending behavior of $\Delta \mu$ on crossing $x_{\mathrm{C}, i}$ is consistent with the second-order nature of magnetic transitions, as indicated by the small triangle and $x_{\mathrm{C}, \mathrm{P}}$ in Fig. 4 . Since $\Delta S \rightarrow 0$
Table 1. Comparison of the chemical potential $(\Delta \mu)$ at $400 \mathrm{~K}$ for Ni-Mn-Ga [57], Ni-Mn-In [25] and Ni-Ti [113] alloys.

\begin{tabular}{lcccc}
\hline Alloy system & $\begin{array}{c}\mathrm{d} T / \mathrm{d} x_{0}^{Z} \\
/ \mathrm{K}\end{array}$ & $\begin{array}{c}\Delta S \\
(\mathrm{~kJ} / \mathrm{mol} \cdot \mathrm{K})\end{array}$ & $\begin{array}{c}\Delta \mu \\
(\mathrm{kJ} / \mathrm{mol})\end{array}$ & \\
\hline $\mathrm{Ni}_{50} \mathrm{Mn}_{50-x} \mathrm{Ga}_{x}$ & 4.3 & 1.6 & 7 & {$[57]$} \\
$\mathrm{Ni}_{50} \mathrm{Mn}_{50-x} \mathrm{In}_{x}$ & 4.4 & 3.0 & 13 & {$[25]$} \\
$\mathrm{Ni}_{x} \mathrm{Ti}_{1-x}$ & 10.6 & 4.5 & 48 & {$[113]$} \\
\hline
\end{tabular}

and $\mathrm{d} T / \mathrm{d} x_{0}^{Z} \rightarrow \infty$ especially for the case of $T_{\mathrm{C}, \mathrm{P}}$, an experimental determination of $\Delta \mu$ near $T_{\mathrm{C}, \mathrm{P}}$ is difficult and a theoretical background is needed for greater understanding.

\section{Kinetics of Ni-Mn-based Magnetic Shape Memory Alloys}

The kinetics of the martensitic transformation in Ni-Mnbased alloys have been paid less attention than thermodynamic phenomena, whereas different phenomenological approaches from several groups have been developed.

Sharma et al. first investigated the relaxation process during martensitic transformation in a Ni-Mn-In alloy [114]. Afterwards, in Ni-Mn-Ga [115], Ni-Co-Mn-In [116-119], Ni-Co-Mn-Sn [120] and Ni-Co-Mn-Sb [121] systems, isothermal behavior has been found for both the forward and reverse martensitic transformations.

As interpretations of the kinetic phenomena, Kustov et al. introduced equations from the magnetic aftereffect [122], within the framework of which the magnetic viscosity coefficient shows a local minimum at the temperature where the fastest transformation can be observed $[117,123]$. On the other hand, based on the nucleation model [124], Fukuda et al. have shown that their experimental observations of time-temperature-transformation (TTT) diagrams can be well explained [125]. Recently, our group also proposed the use of a model based on Seeger's model [126, 127]. The original model had been used for a phenomenological understanding of the critical resolved shear stress (CRSS), which has also proved valid for the application to diffusionless martensitic transformations [128, 129] as well as the case of stress hysteresis in stress-induced martensitic transformation [130]. The following discussions are based on this model.

For the case of MFIT, as in Ni-Mn-In type alloys, the applied magnetic field, $H_{\mathrm{app}}$, which is half of the magnetic field hysteresis $H_{\mathrm{hys}}=H_{\mathrm{A}_{\mathrm{f}}}-H_{\mathrm{M}_{\mathrm{s}}}$, is thought to be divided into two parts: the thermally activated term $H_{\mathrm{TA}}(T)$ and the athermal term $H_{\mu}$ [99]. This is written as

$$
\begin{aligned}
H_{\mathrm{app}}(T) & =H_{\mu}+H_{\mathrm{TA}}(T) \\
& =H_{\mu}+H_{\mathrm{TA}}(0)\left[1-\left(\frac{m k_{\mathrm{B}} T}{Q_{0 \mathrm{~K}}}\right)^{1 / q}\right]^{1 / p},
\end{aligned}
$$

with $H_{\mathrm{TA}}(0)$ being the value of $H_{\mathrm{TA}}(T)$ at $0 \mathrm{~K}, Q_{0 \mathrm{~K}}$ being the activation energy, $k_{\mathrm{B}}$ being the Boltzmann constant, and $m$ being the kinetic coefficient. $p$ and $q$ are the shape parameters describing the activation barrier, which have 


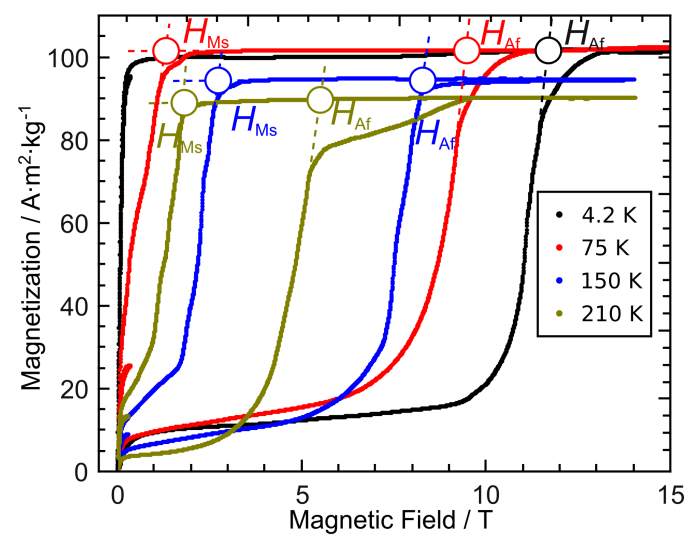

Figure 5. Results for magnetization measurements of a $\mathrm{Ni}_{45} \mathrm{Co}_{5^{-}}$ $\mathrm{Mn}_{36.7} \mathrm{In}_{13.3}$ sample under pulsed magnetic fields. Results for 4.2, 75,150 and $210 \mathrm{~K}$ are shown. Critical magnetic fields, for example, the martensitic transformation starting magnetic field $H_{\mathrm{M}_{\mathrm{s}}}$ and the reverse martensitic finishing magnetic field $H_{\mathrm{Af}_{\mathrm{f}}}$ were determined by extrapolation.

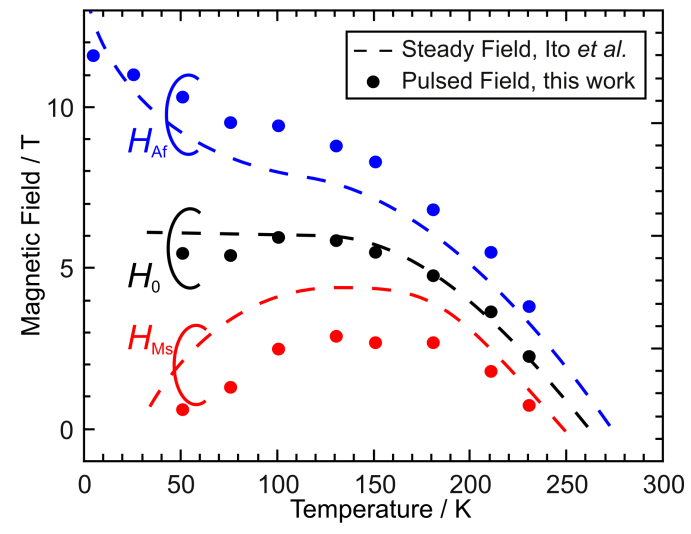

Figure 6. Critical magnetic fields $H_{\mathrm{A}_{\mathrm{f}}}, H_{\mathrm{M}_{\mathrm{s}}}$ and $H_{0}$ under pulsed magnetic fields for $\mathrm{Ni}_{45} \mathrm{Co}_{5} \mathrm{Mn}_{36.7} \mathrm{In}_{13.3}$ alloy determined in Fig. 5 are plotted against the corresponding temperatures. Critical magnetic fields obtained under steady magnetic fields are shown as dashed lines [58].

been obtained as $p=1 / 2, q=3 / 2$ for the case of magnetic field-induced martensitic transformation [99]. $m$ is expressed as

$$
m=\ln \left(\dot{H}_{0} / \dot{H}\right)
$$

where $\dot{H}=\mathrm{d} H / \mathrm{d} t$, which is the sweeping rate of the magnetic field, and $\dot{H}_{0}$ is a constant. In this article, some new results supporting this model are shown.

A $\mathrm{Ni}_{45} \mathrm{Co}_{5} \mathrm{Mn}_{36.7} \mathrm{In}_{13.3}$ sample [58] was subjected to magnetization $(M H)$ measurements, where a condenser bank-powered magnet [131] was used. Figure 5 shows some $M H$ curves under different temperatures. The critical magnetic fields $H_{\mathrm{M}_{\mathrm{s}}}$ and $H_{\mathrm{A}_{\mathrm{f}}}$ were obtained by extrapolation, as shown in the figure.

$H_{\mathrm{M}_{\mathrm{s}}}$ and $H_{\mathrm{A}_{\mathrm{f}}}$ are plotted against temperature in Fig. 6 as filled circles. The dashed lines represent the critical fields determined under a steady magnetic field [58] whose sweeping rate was about $0.005 \mathrm{~T} / \mathrm{s}$. $H_{0}=\left(H_{\mathrm{M}_{\mathrm{s}}}+H_{\mathrm{A}_{\mathrm{f}}}\right) / 2$,

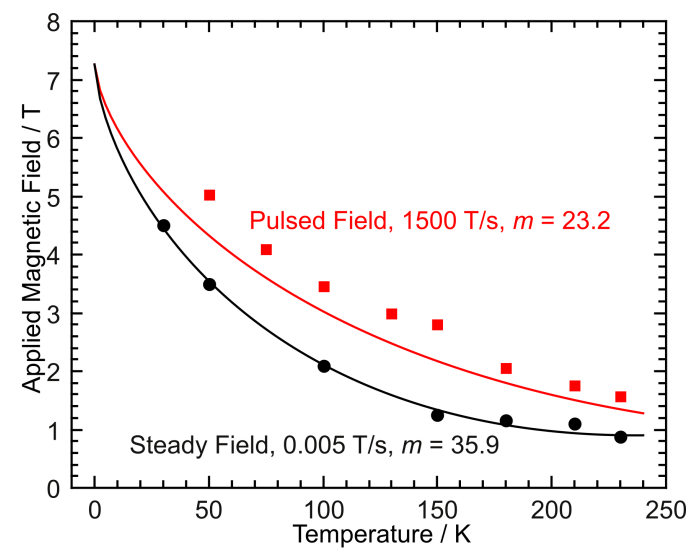

Figure 7. Comparison of the applied magnetic fields for $\mathrm{Ni}_{45} \mathrm{Co}_{5} \mathrm{Mn}_{36.7} \mathrm{In}_{13.3}$ alloy, which is half of the magnetic field hysteresis, between results from steady [58] and pulsed magnetic fields. The black solid line is a fitting curve based on Eq. 7 where the activation energy $Q_{0 \mathrm{~K}}$ was fixed to be $0.7 \mathrm{eV}$ [133]. The same parameters as for the black curve, except for $m$ as in Eq. 8, was used to draw the red curve.

which is thought to be the thermodynamic equilibrium magnetic field [132] in Eq. 5, is also plotted. It can be seen that $H_{0}$ has almost the same values while $H_{\mathrm{M}_{\mathrm{s}}}$ and $H_{\mathrm{A}_{\mathrm{f}}}$ show deviation under different sweeping rates.

In Fig. 7, the $H_{\text {app }}$ is plotted against the temperature for both steady [58] and pulsed magnetic fields. For $H_{\text {app }}$ under steady fields, a fitting against Eq. 7 was conducted. Here, $Q_{0 \mathrm{~K}}$ was set to be $0.7 \mathrm{eV}$ [133] because they have very close heat treatment conditions. $H_{\mu}$ and $H_{\mathrm{TA}}(0)$ were obtained to be $0.9 \mathrm{~T}$ and $6.4 \mathrm{~T}$, respectively, and $m$ was found to be 35.9 for the steady field. Here, if Eq. 7 is valid, one can estimate the value of $\dot{H}_{0}$ to be $1.9 \times 10^{13}$ T/s from Eq. 8 and expect a calculated temperature dependence of $H_{\text {app }}$ for the pulsed field to be consistent with the experimental data by only changing the value of $m$. Therefore $m=23.2$ was calculated using Eq. 8 where $\dot{H}=1500 \mathrm{~T} / \mathrm{s}$ was used, which is a typical sweeping rate for pulsed magnetic fields. This is plotted as the red solid line in Fig. 7 and well reproduces the results of experimental $H_{\text {app }}$ under pulsed fields. Therefore Eq. 7 is considered to be a successful phenomenological model which is valid for the interpretation of kinetic phenomena in the current alloy systems. On the other hand, Fig. 7 also shows us that even at room temperature the $H_{\text {hys }}$ may increase under high sweeping rates of magnetic fields, thus attention should be given to MMSMAs when they are applied to devices where a high response rate is required.

\section{Conclusion}

In summary, a review of the thermodynamics and kinetics of Ni-Mn-based magnetic shape memory alloys was presented.

For thermodynamics:

1. The magnetic phase diagrams of Ni-Mn-Ga and NiMn-In alloys were discussed, along with similar phase diagrams in other quaternary systems. 
2. Some representative reports from the literature were reviewed, some of which focused on the direct measurement of entropy change during martensitic transformation, whereas others examined the martensitic transformation under a magnetic field, uniaxial stress and hydrostatic pressure.

3. The chemical potential change during martensitic transformation was deduced experimentally for $\mathrm{Ni}$ Mn-Ga and Ni-Mn-In systems, where much smaller values than that of Ni-Ti alloys were found.

For kinetics:

1. A phenomenological model based on Seeger's model was reviewed, which interprets the temperature dependence of magnetic field hysteresis $\left(H_{\text {hys }}\right)$.

2. A comparison of $H_{\text {hys }}$ obtained under steady and pulsed magnetic fields was conducted over a wide temperature range. A large difference in the $H_{\text {hys }}$ was found under the condition that the supposed equilibrium magnetic field was consistent.

3. The equation based on Seeger's model was used to fit the $H_{\text {hys }}$ under steady magnetic fields. By only substituting the actual magnetic field sweeping rate, the predicted $H_{\text {hys }}$ showed good agreement with experimental observations.

\section{References}

[1] P.J. Webster, K.R.A. Ziebeck, S.L. Town, M.S. Peak, Philos. Mag. B 49, 295 (1984)

[2] K. Ullakko, J.K. Huang, C. Kantner, R.C. O'Handley, V.V. Kokorin, Appl. Phys. Lett. 69, 1966 (1996)

[3] R.D. James, A. Wuttig, Philos. Mag. A 77, 1273 (1998)

[4] T. Kakeshita, T. Takeuchi, T. Fukuda, M. Tsujiguchi, T. Saburi, R. Oshima, S. Muto, Appl. Phys. Lett. 77, 1502 (2000)

[5] A. Fujita, K. Fukamichi, F. Gejima, R. Kainuma, K. Ishida, Appl. Phys. Lett. 77, 3054 (2000)

[6] M. Wuttig, J. Li, C. Craciunescu, Scr. Mater. 44, 2393 (2001)

[7] K. Oikawa, L. Wulff, T. Iijima, F. Gejima, T. Ohmori, A. Fujita, K. Fukamichi, R. Kainuma, K. Ishida, Appl. Phys. Lett. 79, 3290 (2001)

[8] K. Oikawa, T. Ota, T. Ohmori, Y. Tanaka, H. Morito, A. Fujita, R. Kainuma, K. Fukamichi, K. Ishida, Appl. Phys. Lett. 81, 5201 (2002)

[9] A. Sozinov, A.A. Likhachev, N. Lanska, K. Ullakko, Appl. Phys. Lett. 80, 1746 (2002)

[10] A. Sozinov, N. Lanska, A. Soroka, W. Zou, Appl. Phys. Lett. 102, 021902 (2013)

[11] J. Pons, E. Cesari, C. Segui, F. Masdeu, R. Santamarta, Mater. Sci. Eng., A 481, 57 (2008)

[12] H.E. Karaca, I. Karaman, B. Basaran, Y.J. Chumlyakov, H.J. Maier, Acta Mater. 54, 233 (2006)
[13] Y. Sutou, Y. Imano, N. Koeda, T. Omori, R. Kainuma, K. Ishida, K. Oikawa, Appl. Phys. Lett. 85, 4358 (2004)

[14] R. Kainuma, Y. Imano, W. Ito, Y. Sutou, H. Morito, S. Okamoto, O. Kitakami, K. Oikawa, A. Fujita, T. Kanomata et al., Nature 439, 957 (2006)

[15] R. Kainuma, Y. Imano, W. Ito, H. Morito, Y. Sutou, K. Oikawa, A. Fujita, K. Ishida, S. Okamoto, O. Kitakami et al., Appl. Phys. Lett. 88, 192513 (2006)

[16] S.Y. Yu, Z.X. Cao, L. Ma, G.D. Liu, J.L. Chen, G.H. Wu, B. Zhang, X.X. Zhang, Appl. Phys. Lett. 91, 102507 (2007)

[17] R. Kainuma, W. Ito, R.Y. Umetsu, K. Oikawa, K. Ishida, Appl. Phys. Lett. 93, 091906 (2008)

[18] K. Ando, T. Omori, I. Ohnuma, R. Kainuma, K. Ishida, Appl. Phys. Lett. 95, 212504 (2009)

[19] T. Omori, K. Watanabe, R.Y. Umetsu, R. Kainuma, K. Ishida, Appl. Phys. Lett. 95, 082508 (2009)

[20] T. Omori, K. Ando, M. Okano, X. Xu, Y. Tanaka, I. Ohnuma, R. Kainuma, K. Ishida, Science 333, 68 (2011)

[21] X. Xu, T. Omori, M. Nagasako, A. Okubo, R.Y. Umetsu, T. Kanomata, K. Ishida, R. Kainuma, Appl. Phys. Lett. 103, 164104 (2013)

[22] T. Krenke, M. Acet, E. Wassermann, X. Moya, L. Mañosa, A. Planes, Phys. Rev. B 72, 014412 (2005)

[23] K. Oikawa, W. Ito, Y. Imano, Y. Sutou, R. Kainuma, K. Ishida, S. Okamoto, O. Kitakami, T. Kanomata, Appl. Phys. Lett. 88, 122507 (2006)

[24] M. Khan, I. Dubenko, S. Stadler, N. Ali, J. Phys.: Condens. Matter 20, 235204 (2008)

[25] W. Ito, Y. Imano, R. Kainuma, Y. Sutou, K. Oikawa, K. Ishida, Metall. Mater. Trans. A 38A, 759 (2007)

[26] X. Xu, M. Nagasako, W. Ito, R.Y. Umetsu, T. Kanomata, R. Kainuma, Acta Mater. 61, 6712 (2013)

[27] T. Kanomata, T. Yasuda, S. Sasaki, H. Nishihara, R. Kainuma, W. Ito, K. Oikawa, K. Ishida, K.U. Neumann, K.R.A. Ziebeck, J. Magn. Magn. Mater. 321, 773 (2009)

[28] A. Çakır, L. Righi, F. Albertini, M. Acet, M. Farle, S. Aktürk, J. Appl. Phys. 114, 183912 (2013)

[29] A.G. Popov, E.V. Belozerov, V.V. Sagaradze, N.L. Pecherkina, I.G. Kabanova, V.S. Gaviko, V.I. Khrabrov, Phys. of Metals and Metallography (USSR) 102, 140 (2006)

[30] A.N. Vasil'ev, A.D. Bozhko, V.V. Khovailo, I.E. Dikshtein, V.G. Shavrov, V.D. Buchelnikov, M. Matsumoto, S. Suzuki, T. Takagi, J. Tani, Phys. Rev. B 59, 1113 (1999)

[31] M. Matsumoto, M. Ebisuya, T. Kanomata, H. Yoshida, T. Kaneko, J. Magn. Magn. Mater. 239, 521 (2002)

[32] V.V. Khovaylo, V.D. Buchelnikov, R. Kainuma, V.V. Koledov, M. Ohtsuka, V.G. Shavrov, T. Takagi, S.V. Taskaev, A.N. Vasiliev, Phys. Rev. B 72, 224408 (2005) 
[33] F. Albertini, L. Pareti, A. Paoluzi, L. Morellon, P.A. Algarabel, M.R. Ibarra, L. Righi, Appl. Phys. Lett. 81, 4032 (2002)

[34] R.Y. Umetsu, H. Ando, S. Yamashita, K. Endo, H. Nishihara, R. Kainuma, T. Kanomata, K.R.A. Ziebeck, J. Alloys Compd. 579, 521 (2013)

[35] S.M. Yan, J. Pu, B. Chi, J. Li, Chin Sci Bull 56, 796 (2011)

[36] T. Kanomata, S. Nunoki, K. Endo, M. Kataoka, H. Nishihara, V.V. Khovaylo, R.Y. Umetsu, T. Shishido, M. Nagasako, R. Kainuma et al., Phys. Rev. B 85, 134421 (2012)

[37] C. Jiang, J. Wang, P. Li, A. Jia, H. Xu, Appl. Phys. Lett. 95, 012501 (2009)

[38] T. Kanomata, K. Endo, N. Kudo, R.Y. Umetsu, H. Nishihara, M. Kataoka, M. Nagasako, R. Kainuma, K.R.A. Ziebeck, Metals 3, 114 (2013)

[39] M. Kataoka, K. Endo, N. Kudo, T. Kanomata, H. Nishihara, T. Shishido, R.Y. Umetsu, M. Nagasako, R. Kainuma, Phys. Rev. B 82, 214423 (2010)

[40] D. Soto, F. Alvarado Hernández, H. Flores-Zúñiga, X. Moya, L. Mañosa, A. Planes, S. Aksoy, M. Acet, T. Krenke, Phys. Rev. B 77, 184103 (2008)

[41] Y. Hayasaka, S. Aoto, H. Date, T. Kanomata, X. Xu, R.Y. Umetsu, M. Nagasako, T. Omori, R. Kainuma, T. Sakon et al., J. Alloys Compd. 591, 280 (2014)

[42] Y. Wang, C. Huang, J. Gao, S. Yang, X. Ding, X. Song, X. Ren, Appl. Phys. Lett. 101, 101913 (2012)

[43] Y.V. Kaletina, E.G. Gerasimov, Phys. Solid State 56, 1634 (2014)

[44] K. Fukushima, K. Sano, T. Kanomata, H. Nishihara, Y. Furutani, T. Shishido, W. Ito, R.Y. Umetsu, R. Kainuma, K. Oikawa et al., Scr. Mater. 61, 813 (2009)

[45] Y. Kim, W.B. Han, H.S. Kim, H.H. An, C.S. Yoon, J. Alloys Compd. 557, 265 (2013)

[46] X. Xu, W. Ito, M. Tokunaga, T. Kihara, K. Oka, R.Y. Umetsu, T. Kanomata, R. Kainuma, Metals 3, 298 (2013)

[47] H.C. Xuan, F.H. Chen, P.D. Han, D.H. Wang, Y.W. $\mathrm{Du}$, Intermetallics 47, 31 (2014)

[48] D.Y. Cong, S. Roth, L. Schultz, Acta Mater. 60, 5335 (2012)

[49] X. Xu, T. Kanomata, R. Kainuma, Acta Mater. 79, 159 (2014)

[50] V.A. Chernenko, E. Cesari, V.V. Kokorin, I.N. Vitenko, Scr. Metall. Mater. 33, 1239 (1995)

[51] S.K. Wu, S.T. Yang, Mater. Lett. 57, 4291 (2003)

[52] V.V. Khovailo, K. Oikawa, T. Abe, T. Takagi, J. Appl. Phys. 93, 8483 (2003)

[53] V. Recarte, J.I. Pérez-Landazábal, V. SánchezAlarcos, V. Zablotskii, E. Cesari, S. Kustov, Acta Mater. 60, 3168 (2012)
[54] N.V.R. Rao, V. Chandrasekaran, K.G. Suresh, J. Appl. Phys. 108, 043913 (2010)

[55] Z. Liu, Z. Wu, H. Yang, Y. Liu, E. Liu, H. Zhang, G. Wu, Intermetallics 18, 1690 (2010)

[56] S. Kustov, M.L. Corro, J. Pons, E. Cesari, Appl. Phys. Lett. 94, 191901 (2009)

[57] X. Xu, W. Ito, T. Kanomata, R. Kainuma, Entropy 16, 1808 (2014)

[58] W. Ito, K. Ito, R.Y. Umetsu, R. Kainuma, K. Koyama, K. Watanabe, A. Fujita, K. Oikawa, K. Ishida, T. Kanomata, Appl. Phys. Lett. 92, 021908 (2008)

[59] E. Cesari, S. Kustov, D. Salas, Mater Sci Forum 684, 49 (2011)

[60] P. Wollants, M. Debonte, J.R. Roos, Z. Metallk. 70, 113 (1979)

[61] S. Miyazaki, K. Otsuka, Y. Suzuki, Scr. Metall. 15, 287 (1981)

[62] V.V. Martynov, V.V. Kokorin, J. Phys. III 2, 739 (1992)

[63] H.E. Karaca, I. Karaman, A. Brewer, B. Basaran, Y.I. Chumlyakov, H.J. Maier, Scr. Mater. 58, 815 (2008)

[64] X. Xu, W. Ito, R.Y. Umetsu, R. Kainuma, K. Ishida, Appl. Phys. Lett. 95, 181905 (2009)

[65] J.A. Monroe, I. Karaman, B. Basaran, W. Ito, R.Y. Umetsu, R. Kainuma, K. Koyama, Y.I. Chumlyakov, Acta Mater. 60, 6883 (2012)

[66] D. Bourgault, L. Porcar, C. Bruyere, P. Jacquet, P. Courtois, Rev. Sci. Instrum. 84, 013905 (2013)

[67] K. Niitsu, X. Xu, R.Y. Umetsu, R. Kainuma, Appl. Phys. Lett. 103, 242406 (2013)

[68] Y.D. Wang, Y. Ren, E.W. Huang, Z.H. Nie, G. Wang, Y.D. Liu, J.N. Deng, L. Zuo, H. Choo, P.K. Liaw et al., Appl. Phys. Lett. 90, 101917 (2007)

[69] W. Ito, B. Basaran, R.Y. Umetsu, I. Karaman, R. Kainuma, K. Ishida, Mater. Trans. 51, 525 (2010)

[70] M. Annaorazov, S. Nikitin, A. Tyurin, K. Asatryan, A. Dovletov, J. Appl. Phys. 79, 1689 (1996)

[71] E. Bonnot, R. Romero, L. Manosa, E. Vives, A. Planes, Phys. Rev. Lett. 100, 125901 (2008)

[72] B. Lu, F. Xiao, A. Yan, J. Liu, Appl. Phys. Lett. 105, 161905 (2014)

[73] V. Chernenko, J. Phys. IV 5, 77 (1995)

[74] L. Manosa, D. Gonzalez-Alonso, A. Planes, E. Bonnot, M. Barrio, J.L. Tamarit, S. Aksoy, M. Acet, Nat. Mater. 9, 478 (2010)

[75] T. Kanomata, K. Shirakawa, T. Kaneko, J. Magn. Magn. Mater. 65, 76 (1987)

[76] T. Miura, Y. Adachi, K. Endo, R. Kainuma, T. Kanomata, J Kor Phys Soc 62, 1879 (2013)

[77] J. Kim, T. Taniguchi, T. Fukuda, T. Kakeshita, Mater. Trans. 46, 1928 (2005)

[78] H. Maeda, T. Fukuda, T. Kakeshita, J. Alloys Compd. 509, 7840 (2011) 
[79] P.I. Polyakov, V.V. Slyusarev, S.M. Konoplyuk, V.V. Kokorin, Y.S. Sernenova, Mater. Lett. 67, 263 (2012)

[80] V.K. Sharma, M.K. Chattopadhyay, S.B. Roy, J. Phys.: Condens. Matter 23, 366001 (2011)

[81] N.V.R. Rao, M.M. Raja, S.E. Muthu, S. Arumugam, S. Pandian, J. Appl. Phys. 116, 223904 (2014)

[82] J. Kamarad, F. Albertini, Z. Arnold, S. Fabbrici, J. Kastil, Acta Mater. 77, 60 (2014)

[83] Y. Adachi, M. Kato, T. Kanomata, D. Kikuchi, X. Xu, R.Y. Umetsu, R. Kainuma, K.R.A. Ziebeck, Physica B 464, 83 (2015)

[84] T. Krenke, E. Duman, M. Acet, E. Wassermann, X. Moya, L. Manosa, A. Planes, Nat. Mater. 4, 450 (2005)

[85] A. Planes, L. Mañosa, M. Acet, J. Phys.: Condens. Matter 21, 233201 (2009)

[86] V. Franco, J.S. Blazquez, B. Ingale, A. Conde, Annu. Rev. Mater. Res. 42, 305 (2012)

[87] P.J. Webster, R.M. Mankikar, J. Magn. Magn. Mater. 42, 300 (1984)

[88] V.A. Chernenko, V.A. Lvov, T. Kanomata, T. Kakeshita, K. Koyama, S. Besseghini, Mater. Trans. 47, 635 (2006)

[89] J.H. Kim, F. Inaba, T. Fukuda, T. Kakeshita, Acta Mater. 54, 493 (2006)

[90] S. Fabbrici, J. Kamarad, Z. Arnold, F. Casoli, A. Paoluzi, F. Bolzoni, R. Cabassi, M. Solzi, G. Porcari, C. Pernechele et al., Acta Mater. 59, 412 (2011)

[91] O. Heczko, L. Straka, N. Lanska, K. Ullakko, J. Enkovaara, J. Appl. Phys. 91, 8228 (2002)

[92] T. Krenke, E. Duman, M. Acet, E.F. Wassermann, X. Moya, L. Manosa, A. Planes, E. Suard, B. Ouladdiaf, Phys. Rev. B 75, 104414 (2007)

[93] R.Y. Umetsu, W. Ito, K. Ito, K. Koyama, A. Fujita, K. Oikawa, T. Kanomata, R. Kainuma, K. Ishida, Scr. Mater. 60, 25 (2009)

[94] R.Y. Umetsu, Y. Kusakari, T. Kanomata, K. Suga, Y. Sawai, K. Kindo, K. Oikawa, R. Kainuma, K. Ishida, J. Phys. D-Appl. Phys. 42, 075003 (2009)

[95] J.M. Barandiaran, V.A. Chernenko, E. Cesari, D. Salas, P. Lazpita, J. Gutierrez, I. Orue, Appl. Phys. Lett. 102, 071904 (2013)

[96] M.G. Zavareh, C.S. Mejia, A.K. Nayak, Y. Skourski, J. Wosnitza, C. Felser, M. Nicklas, Appl. Phys. Lett. 106, 071904 (2015)

[97] Y.D. Wang, E.W. Huang, Y. Ren, Z.H. Nie, G. Wang, Y.D. Liu, J.N. Deng, H. Choo, P.K. Liaw, D.E. Brown et al., Acta Mater. 56, 913 (2008)

[98] X. Xu, W. Ito, I. Katakura, M. Tokunaga, R. Kainuma, Scr. Mater. 65, 946 (2011)

[99] R.Y. Umetsu, K. Endo, A. Kondo, K. Kindo, W. Ito, X. Xu, T. Kanomata, R. Kainuma, Mater. Trans. 54, 291 (2013)

[100] T. Kihara, X. Xu, W. Ito, R. Kainuma, M. Tokunaga, Phys. Rev. B 90, 214409 (2014)
[101] A.K. Nayak, C.S. Mejia, S.W. D’Souza, S. Chadov, Y. Skourski, C. Felser, M. Nicklas, Phys. Rev. B 90, 220408 (2014)

[102] R.Y. Umetsu, K. Ito, W. Ito, K. Koyama, T. Kanomata, K. Ishida, R. Kainuma, J. Alloys Compd. 509, 1389 (2011)

[103] S.Y. Yu, L. Ma, G.D. Liu, Z.H. Liu, J.L. Chen, Z.X. Cao, G.H. Wu, B. Zhang, X.X. Zhang, Appl. Phys. Lett. 90, 242501 (2007)

[104] R.Y. Umetsu, X. Xu, W. Ito, T. Kihara, K. Takahashi, M. Tokunaga, R. Kainuma, Metals 4, 609 (2014)

[105] X. Xu, W. Ito, M. Tokunaga, R.Y. Umetsu, R. Kainuma, K. Ishida, Mater. Trans. 51, 1357 (2010)

[106] Y. Mitsui, K. Koyama, W. Ito, R.Y. Umetsu, R. Kainuma, K. Watanabe, Mater. Trans. 51, 1648 (2010)

[107] X. Xu, I. Katakura, T. Kihara, M. Tokunaga, W. Ito, R.Y. Umetsu, R. Kainuma, Mater. Trans. 3, 357 (2013)

[108] X. Xu, W. Ito, R.Y. Umetsu, K. Koyama, R. Kainuma, K. Ishida, Mater. Trans. 51, 469 (2010)

[109] G. Porcari, S. Fabbrici, C. Pernechele, F. Albertini, M. Buzzi, A. Paoluzi, J. Kamarad, Z. Arnold, M. Solzi, Phys. Rev. B 85, 024414 (2012)

[110] T. Sakon, K. Sasaki, D. Numakura, M. Abe, H. Nojiri, Y. Adachi, T. Kanomata, Mater. Trans. 54, 9 (2013)

[111] T. Kihara, I. Katakura, M. Tokunaga, A. Matsuo, K. Kawaguchi, A. Kondo, K. Kindo, W. Ito, X. Xu, R. Kainuma, J. Alloys Compd. 577, S722 (2013)

[112] Y.D. Wang, E.W. Huang, Y. Ren, Z.H. Nie, G. Wang, Y.D. Liu, J.N. Deng, H. Choo, P.K. Liaw, D.E. Brown et al., Acta Mater. 56, 913 (2008)

[113] K. Niitsu, Y. Kimura, X. Xu, R. Kainuma, Shape Memory and Superelasticity 1, xxx (2015)

[114] V.K. Sharma, M.K. Chattopadhyay, S.B. Roy, Phys. Rev. B 76, 140401 (2007)

[115] C. Gomez-Polo, J.I. Perez-Landazabal, V. Recarte, V. Sanchez-Alarcos, V.A. Chernenko, J. Phys.: Condens. Matter 21, 026020 (2009)

[116] W. Ito, R.Y. Umetsu, R. Kainuma, T. Kakeshita, K. Ishida, Scr. Mater. 63, 73 (2010)

[117] S. Kustov, I. Golovin, M. Corró, E. Cesari, J. Appl. Phys. 107, 053525 (2010)

[118] Y. Lee, M. Todai, T. Okuyama, T. Fukuda, T. Kakeshita, R. Kainuma, Scr. Mater. 64, 927 (2011)

[119] J.I. Pérez-Landazábal, V. Recarte, V. SánchezAlarcos, S. Kustov, E. Cesari, J. Alloys Compd. 536, S277 (2012)

[120] F. Chen, Y.X. Tong, B. Tian, Y.F. Zheng, Y. Liu, Intermetallics 18, 188 (2010)

[121] A.K. Nayak, K.G. Suresh, A.K. Nigam, J. Appl. Phys. 109, 07A906 (2011) 
[122] G. Bertotti, Hysteresis in magnetism: for physicists, materials scientists, and engineers (Academic Press, 1998)

[123] J.I. Perez-Landazabal, V. Recarte, J. Torrens-Serra, E. Cesari, Acta Mater. 71, 117 (2014)

[124] T. Kakeshita, K. Kuroiwa, K. Shimizu, T. Ikeda, A. Yamagishi, M. Date, Mater Trans JIM 34, 423 (1993)

[125] T. Fukuda, T. Kakeshita, Y.H. Lee, Acta Mater. 81, 121 (2014)

[126] A. Seeger, Philos. Mag. 45, 771 (1954)

[127] W.F. Kocks, Progr. Mater. Sci. 19, 1 (1975)
[128] G. Ghosh, G.B. Olson, Acta Metall Mater 42, 3361 (1994)

[129] G. Ghosh, G.B. Olson, Acta Metall Mater 42, 3371 (1994)

[130] K. Niitsu, T. Omori, R. Kainuma, Appl. Phys. Lett. 102, 231915 (2013)

[131] K. Kindo, Physica B 294, 585 (2001)

[132] H.C. Tong, C.M. Wayman, Acta Metall. 22, 887 (1974)

[133] X. Xu, T. Kihara, M. Tokunaga, A. Matsuo, W. Ito, R.Y. Umetsu, K. Kindo, R. Kainuma, Appl. Phys. Lett. 103, 122406 (2013) 
